\title{
Anne Cova, Bruno Dumons (éd.), Destins de femmes. Religion, culture et société (France, $\mathrm{XIX}^{\mathrm{e}}{ }^{-}$ $\mathrm{xx}^{\mathrm{e}}$ siècles)
}

\section{Céline Béraud}

\section{(2) OpenEdition}

Journals

Édition électronique

URL : http://journals.openedition.org/assr/23468

DOI : $10.4000 /$ assr. 23468

ISSN : $1777-5825$

Éditeur

Éditions de l'EHESS

\section{Édition imprimée}

Date de publication : 31 décembre 2011

Pagination : 149

ISBN : 9782713223273

ISSN : 0335-5985

\section{Référence électronique}

Céline Béraud, « Anne Cova, Bruno Dumons (éd.), Destins de femmes. Religion, culture et société (France, $\mathrm{xI} \mathrm{x}^{\mathrm{e}} \mathrm{x} \mathrm{x} \mathrm{e}^{\mathrm{e}}$ siècles) », Archives de sciences sociales des religions [En ligne], 156 | octobre-décembre 2011, document 156-37, mis en ligne le 14 février 2012, consulté le 21 septembre 2020. URL : http:// journals.openedition.org/assr/23468; DOI : https://doi.org/10.4000/assr.23468

Ce document a été généré automatiquement le 21 septembre 2020.

(c) Archives de sciences sociales des religions 


\title{
Anne Cova, Bruno Dumons (éd.), Destins de femmes. Religion, culture et société (France, $\mathrm{XIX}^{\mathrm{e}-\mathrm{XX}}{ }^{\mathrm{e}}$ siècles)
}

\author{
Céline Béraud
}

\section{RÉFÉRENCE}

Anne Cova, Bruno Dumons (éd.), Destins de femmes. Religion, culture et société (France, $\mathrm{XIX}^{\mathrm{e}-\mathrm{XX}}{ }^{\mathrm{e}}$ siècles), Paris, Letouzey et Ané, coll. « Mémoire chrétienne au présent », 2010.

(Préface d'Yves-Marie Hilaire et Jean-Marie Mayeur), 466 p.

1 L'engouement éditorial pour les dictionnaires et notamment les dictionnaires biographiques, y compris dans le champ religieux (dont le Dictionnaire des évêques de France au $\mathrm{XX}^{e}$ siècle paru au Cerf en 2010 sous la direction de Dominique-Marie Dauzet et Frédéric Le Moigne offre un exemple récent), ne semble pas tari. On ne peut que se féliciter que le présent ouvrage soit consacré à des personnalités féminines.

2 L'ampleur du travail réalisé est impressionnante : 260 notices rédigées par plus de 80 auteur-e-s. La substantielle et stimulante introduction rédigée par Anne Cova et Bruno Dumons, tous les deux connus notamment pour leurs recherches sur les femmes catholiques, présente clairement le projet. Il s'agit de rendre compte d'itinéraires de figures féminines considérées comme «ayant marqué l'histoire contemporaine du fait religieux» (p.21), par leur appartenance au christianisme et au judaïsme, mais également à la laïcité, voire à l'anticléricalisme, à la franc-maçonnerie ou encore à la libre-pensée. Les bornes temporelles sont la Révolution française d'une part, mai 68 d'autre part. D'un point de vue méthodologique, l'entreprise n'est pas aisée, car les traces laissées par certaines de ces femmes dans les archives sont parfois minces.

3 La mise en perspective historiographique est fort bien menée. La question des femmes et de la religion a longtemps été réduite aux « silences de l'histoire " pour reprendre l'expression de Michelle Perrot. Elle a été ignorée tant par l'histoire religieuse que par 
l'histoire sociale, du moins en France. L'apport de chercheur-se-s américain-e-s (Bonnie Smith ou encore Ralph Gibson) se révèle par comparaison précurseur. Les choses changent à partir des années 1980 avec tout particulièrement les travaux de Claude Langlois sur le "catholicisme au féminin" puis ceux de Florence Rochefort sur féminismes et protestantisme. En 1995, le fait que le deuxième numéro de la revue Clio soit consacré aux femmes et aux religions (sous la direction de Claudine Leduc et d'Agnès Fine) est alors révélateur du chemin déjà parcouru.

4 La démarche prosopographique n'est pas gratuite. Elle permet de dégager une typologie des engagements féminins. Au XIX ${ }^{e}$ siècle: religieuses et fondatrices de congrégations, dames d'œuvres, mystiques (Catherine Labouré, Bernadette Soubirous, Françoise-Mélanie Calvat), enseignantes et pédagogues (Julie Favre, Pauline Kergomard), écrivaines à l'affiliation religieuse parfois incertaine et discutée (George Sand par exemple), mais également figures anticléricales (Clémence Royer, traductrice de Darwin; Maria Deraismes, théoricienne du féminisme, libre-penseuse et francmaçonne). $\mathrm{Au} \mathrm{xx}{ }^{e}$ siècle : des mystiques encore (Thérèse Martin et Marthe Robin bien sûr), des ligueuses en début de période (Marie Frossard), mais surtout des militantes de l'Action Catholique, des figures du renouveau catéchétique et du scoutisme, des résistantes (Renée Bédarida, Marie-Louise David, Geneviève de Gaulle), des pédagogues (Madeleine Daniélou, Jeanne Lebrun), des intellectuelles (France Quéré, Annie Kriegel, Marguerite Harl et ses travaux sur la Septante), ainsi que des femmes politiques (Cécile Brunschvicg, Marie-Madeleine Dienesch), des syndicalistes et des artistes (Germaine Richier dont le Christ d'Assy fit scandale). Le type d'engagement est mentionné en tête de notice, mais un index thématique en aurait facilité l'accès.

Quelques parcours de vie donnent à voir une suite de réinvestissements militants: comme celui de Louise Blanquart qui passe de l'Action Catholique à la cause des prêtres ouvriers, puis de la CGT et du PC où elle s'engage pour les travailleuses (période où elle s'éloigne de l'Église et de la croyance) aux Verts. Certains témoignent de sorties de la religion, d'affiliations confessionnelles fragiles ou encore de conversions. Quelques femmes ont œuvré pour l'œcuménisme (Hélène Iswolky), voire le dialogue interreligieux (Colette Kessler).

6 Trois notices sur quatre concernent des personnalités qui ont vécu au $\mathrm{Xx}^{\mathrm{e}}$ siècle. Les catholiques forment la même proportion de l'ensemble. Si la part belle est faite aux catholiques, les protestantes (dans leurs différentes dénominations) ne sont pas oubliées avec notamment Esther Carpentier, "évangéliste de grand chemin », ou encore Hélène Biolley, qui accompagna les débuts du pentecôtisme en France. Une des figures les plus connues de l'orthodoxie en France est certainement Elisabeth BehrSiegel. L'apport est un peu moins vaste pour le judaïsme. Pour rendre compte d'évolutions plus récentes, une notice est consacrée à la première femme rabbin en France, Pauline Bebe, pourtant née en 1964. Rien n'est dit sur les autres religions.

7 On pourrait bien sûr discuter certains choix, regretter des oublis. Mais l'ensemble se révèle extrêmement riche et fort précieux pour celles et ceux qui s'intéressent tant à l'histoire religieuse qu'à l'histoire des femmes. Signalons également l'utile bibliographie en fin de volume. 